\title{
Interaction between Trichomonas vaginalis and the Prostate Epithelium
}

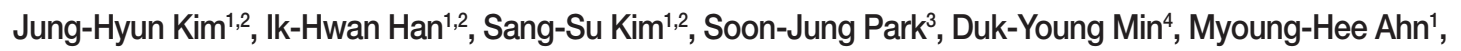 \\ Jae-Sook Ryu', ${ }^{1,2}$ \\ ${ }^{1}$ Department of Environmental Biology and Medical Parasitology, ${ }^{2}$ Department of Biomedical Science, Graduate School of Biomedical Science and \\ Engineering, Hanyang University College of Medicine, Seoul 04763, Korea; ${ }^{3}$ Department of Environmental Medical Biology and Institute of Tropical \\ Medicine, Yonsei University College of Medicine, Seoul 03722, Korea; ${ }^{4}$ Department of Microbiology and Immunology, Eulji University College of \\ Medicine, Daejeon 35233, Korea
}

\begin{abstract}
Most men infected with Trichomonas vaginalis are asymptomatic and can remain undiagnosed and untreated. This has been hypothesized to result in chronic persistent prostatic infection. Adhesion of the protozoan organisms to mucosal cells is considered a first and prerequisite step for T. vaginalis infection. Adhesion of $T$. vaginalis to prostate epithelial cells has not yet been observed; however, there are several reports about inflammation of prostate epithelial cells induced by $T$. vaginalis. The aim of this study was to investigate whether adhesion and cytotoxicity of $T$. vaginalis are involved in inflammation of prostate epithelial cells. When RWPE-1 cells were infected with T. vaginalis (1:0.4 or 1:4), adhesion of $T$. vaginalis continuously increased for $24 \mathrm{hr}$ or $3 \mathrm{hr}$, respectively. The cytotoxicity of prostate epithelial cells infected with $T$. vaginalis (RWPE-1: T. vaginalis $=1: 0.4$ ) increased at $9 \mathrm{hr}$; at an infection ratio of 1:4, cytotoxicity increased after $3 \mathrm{hr}$. When the RWPE-1 to T. vaginalis ratio was 1:0.4 or 1:4, production of IL-1 $\beta$, IL-6, CCL2, and CXCL8 also increased. Epithelial-mesenchymal transition (EMT) was verified by measuring decreased E-cadherin and increased vimentin expression at $24 \mathrm{hr}$ and $48 \mathrm{hr}$. Taken together, the results indicate that $T$. vaginalis adhered to prostate epithelial cells, causing cytotoxicity, pro-inflammatory cytokine production, and EMT. Our findings suggest for the first time that $T$. vaginalis may induce inflammation via adhesion to normal prostate epithelial cells.
\end{abstract}

Key words: Trichomonas vaginalis, epithelial cell, cell adhesion, inflammation

Trichomonas vaginalis, a parasitic protozoan, causes the sexually transmitted disease trichomoniasis, a common infection of the urogenital system [1]. The World Health Organization (WHO) estimated that over a half of the 276.4 million new $T$. vaginalis infections occur each year in men [2]. Because trichomoniasis is asymptomatic in over $75 \%$ of infected men, it can remain undiagnosed and untreated, which has been hypothesized to result in chronic persistent prostatic infection $[3,4]$. In addition, T. vaginalis has been detected recently in the urine of patients with prostatitis and in the prostate tissue of patients with benign prostatic hyperplasia or prostate cancer [5-7]. However, the host-parasite interaction of trichomoniasis remains incompletely understood in the prostate.

Adhesion of the organisms to mucosal cells is considered a

\footnotetext{
- Received 18 January 2017, revised 9 February 2017, accepted 22 February 2017.

*Corresponding author (jsryu@hanyang.ac.kr)

(C) 2017, Korean Society for Parasitology and Tropical Medicine

This is an Open Access article distributed under the terms of the Creative Commons

Attribution Non-Commercial License (http://creativecommons.org/licenses/by-nc/4.0) which permits unrestricted non-commercial use, distribution, and reproduction in any

medium, provided the original work is properly cited.
}

first and prerequisite step for T. vaginalis infections [8,9]. When T. vaginalis was added to epithelial cells, the parasitic body changed to a more elongated shape with pseudopodia, showing high adherence to primary vaginal epithelial cells. In contrast, the morphology of $T$. vaginalis did not change when added to a cervical cancer epithelial cell line (HeLa) [10]. Therefore, T. vaginalis is able to recognize and specifically bind to host tissues. Adhesion of T. vaginalis to different cell types such as renal epithelial cells, colon epithelial cells, sperm, fibroblasts, leukocytes, or breast myocytes has been previously reported [11-15]. However, adhesion of T. vaginalis to prostate epithelial cells has not yet been observed, although there are several reports on T. vaginalis-induced inflammation of prostate epithelial cells.

The aim of this study was to investigate whether adhesion and cytotoxicity of T. vaginalis could lead to inflammation of prostate epithelial cells. Our findings suggested that T. vaginalis adhered and caused cytotoxicity to prostate epithelial cells, with subsequent induction of inflammation and epithelial-mesenchymal transition (EMT). 
T. vaginalis isolate T016 was grown in TYM media supplemented with $10 \%$ heat-inactivated horse serum. The human prostate epithelial cells (RWPE-1 cell line) were cultured in keratinocyte serum-free medium (K-SFM) containing $5 \mathrm{ng} / \mathrm{ml} \mathrm{hu-}$ man recombinant epidermal growth factor and $25 \mu \mathrm{g}$ bovine pituitary extract supplemented with 5\% FBS.

To confirm the adhesion of live T. vaginalis, RWPE-1 cells were incubated with T. vaginalis (RWPE-1: T. vaginalis $=1: 0.4$ or 1:4) for $30 \mathrm{~min}, 3,6,9,24$, and $48 \mathrm{hr}$. T. vaginalis was stained with a CellTrackerOrange Fluorescent Probe (Invitrogen, Carlsbad, California, USA) according to the manufacturer's instructions. Briefly, T. vaginalis was suspended in CellTrackerOrange solution, which was diluted to $0.5 \mu \mathrm{M}$ in Hank's solution (Invitrogen). After $30 \mathrm{~min}$, the stained T. vaginalis was added to a monolayer of RWPE-1. After incubation, adherence of T. vaginalis was examined with a fluorescence microscope (Leica, Wetzlar, Germany), and images were analyzed by ImageJ.

To determine the effects of live T. vaginalis on the cytotoxicity of prostate epithelial cells, RWPE-1 cells were seeded on 96well plates and cultured in complete K-SFM medium with 5\% FBS. After $24 \mathrm{hr}$, the RWPE-1 medium was changed to serumfree RPMI1640 medium and incubated for $24 \mathrm{hr}$. T. vaginalis (RWPE-1:T. vaginalis $=1: 0.4$ or 1:4) was then added into the RWPE-1 and incubated for various times. Cytotoxicity was analyzed using a CCK-8 assay. CCK-8 reagent (Enzo Life Sciences, Farmingdale, New York, USA) was added to each well for $2 \mathrm{hr}$ prior to obtaining the spectrophotometric reading according to the manufacturer's directions. The CCK-8 assay is a sensitive colorimetric assay to determine the number of viable cells in cell proliferation and cytotoxicity assays. The CCK-8 reagent is reduced by dehydrogenases, yielding a water-soluble formazan dye. The amount of dye generated is directly proportional to the number of living cells.

The production of inflammatory cytokines by RWPE-1 cells incubated with T. vaginalis (RWPE-1: T. vaginalis $=1: 0.4$ or 1:4) for 9, 24, and $48 \mathrm{hr}$ was measured using an ELISA for IL-1 $\beta$, IL6, CCL2, and CXCL8 (BD Biosciences, San Diego, California, $\mathrm{CA}$ ). The data are presented as the mean $\pm \mathrm{SD}$ of 3 independent experiments.

To examine the epithelial-mesenchymal transition (EMT), expression of E-cadherin (epithelial marker), and vimentin (mesenchymal marker) was assessed using fluorescence microscopy. Briefly, RWPE-1 cells were grown on a glass coverslip in a 12-well plate (Corning) and incubated with T. vaginalis for $24 \mathrm{hr}$. The cells were fixed with $4 \%$ paraformaldehyde at $-20^{\circ} \mathrm{C}$ for $10 \mathrm{~min}$ and blocked with $0.1 \%$ normal goat serum at room temperature for $1 \mathrm{hr}$. After being washed with PBS 3 times, the glass cover slips were incubated with anti-E-cadherin antibody (1:250, mouse monoclonal, Cell signaling) or antivimentin antibody (1:500, rabbit polyclonal, Abcam) overnight at $4^{\circ} \mathrm{C}$. They were then washed and stained with $\mathrm{Cy}^{\mathrm{TM} 3}$ AffiniPure donkey anti-mouse IgG (1:500, Jackson Immuno Research, West Grove, Philadelphia, USA) or Alexa 594-labelled goat anti-rabbit $\operatorname{lgG}$ (\#A11012, 1:500, Invitrogen) at $37^{\circ} \mathrm{C}$ for $1 \mathrm{hr}$. The cover slips were mounted using Vectashield mounting medium (Vector Laboratories, Burlingame, California, USA) and stained with DAPI to visualize the nuclei. Fluorescence was then measured with a fluorescence microscope (Las Software, Leica).

Western blotting was also performed to confirm EMT. RWPE1 cells were incubated with T. vaginalis (RWPE-1: T. vaginalis= 1:0.4) for $48 \mathrm{hr}$, separated by SDS-PAGE on a 12\% polyacrylamide gel, and transferred to an Immun-Blot ${ }^{\mathbb{B}}$ PVDF membrane (Bio-Rad, Quarry Bay, Hong Kong). The membranes were probed with anti-E-cadherin antibody (1:1,000; Cell signaling) or anti-vimentin antibody (1:1,000; cell signaling) primary antibodies overnight at $4^{\circ} \mathrm{C}$. The membranes were incubated with goat anti-rabbit IgG polyclonal antibody (1:10,000; ADISAB300-J, Enzo Life Sciences) for $1 \mathrm{hr}$ at room temperature. The blots were visualized using Chemiluminescent Sensitive Plus HRP Microwell and/or Membrane Substrate (SurModics, Minneapolis, Minneapolis, USA). The signals were measured with a Chemi-Doc (Bio-Rad, Hercules, California, USA).

When prostate epithelial cells were reacted with $T$. vaginalis at a ratio of 1:0.4, adhesion of $T$. vaginalis began after $30 \mathrm{~min}$ and increased continuously for $24 \mathrm{hr}$. In contrast, at a ratio of 1:4, adherence of T. vaginalis to prostate epithelial cells peaked at $3 \mathrm{hr}$, after which the level sharply decreased (Fig. 1A, B). When RWPE-1 cells were infected with T. vaginalis (RWPE-1: T. vaginalis =1:0.4), the cytotoxicity of prostate epithelial cells increased gradually from $9 \mathrm{hr}(2.0 \%)$ to $48 \mathrm{hr}(26.4 \%)$. However, at a ratio of 1:4, the cytotoxicity of prostate epithelial cells increased from $3 \mathrm{hr}$ to $48 \mathrm{hr}$, with a maximum level of 91.5\% (Fig. 1C). In contrast to T. vaginalis-infected groups, cytotoxicity did not appear over a $48 \mathrm{hr}$ period in the control group (RWPE only). This result was consistent with the results of Lustig et al. [16], who identified T. vaginalis contact-dependent cytolysis of epithelial cells. The 1:0.4 ratio showed higher adhesion and lower cytotoxicity at $24 \mathrm{hr}$. T. vaginalis is a microaerophilic anaerobic protozoa [17]. In contrast to the vagina, the prostate is 
A

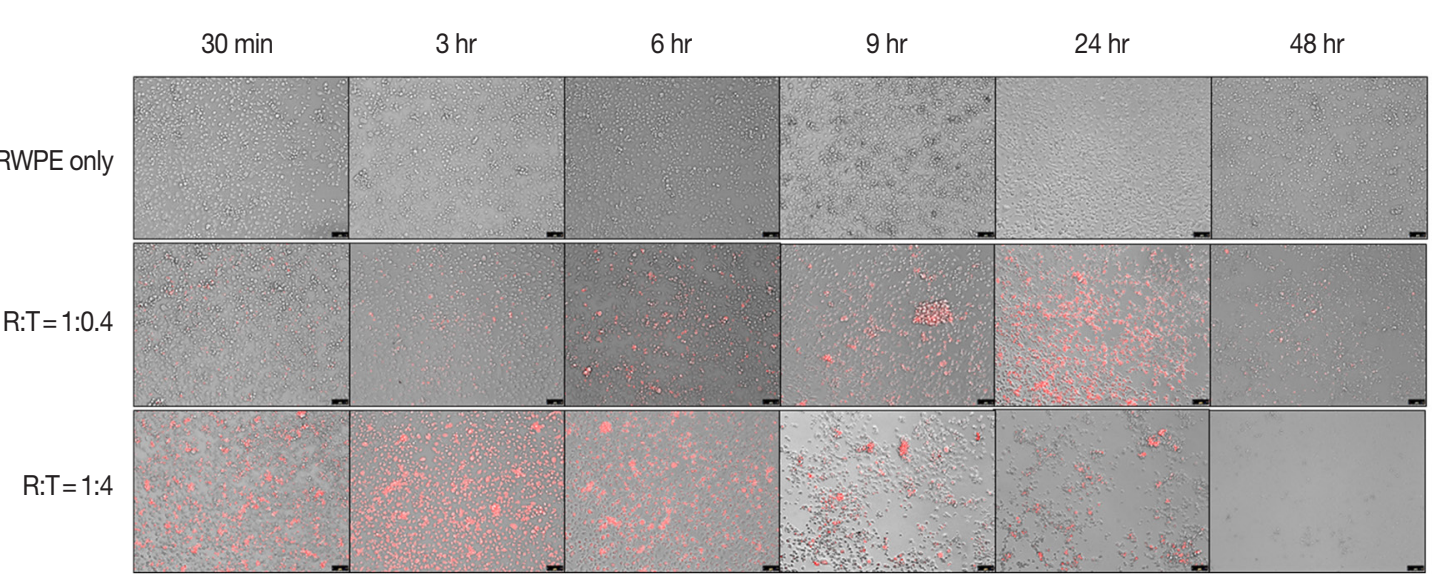

B

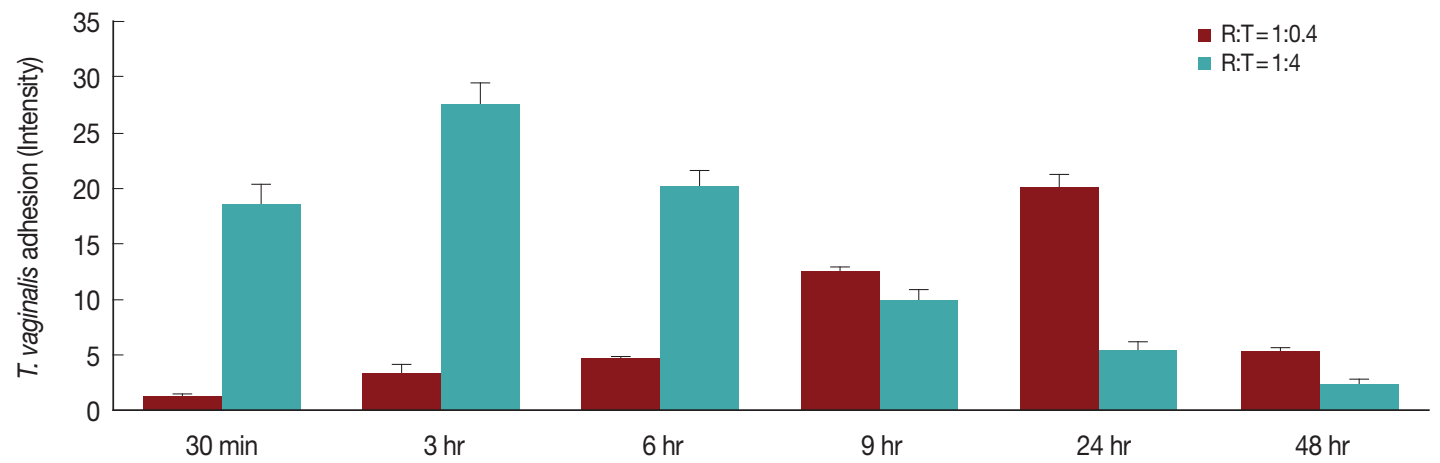

C

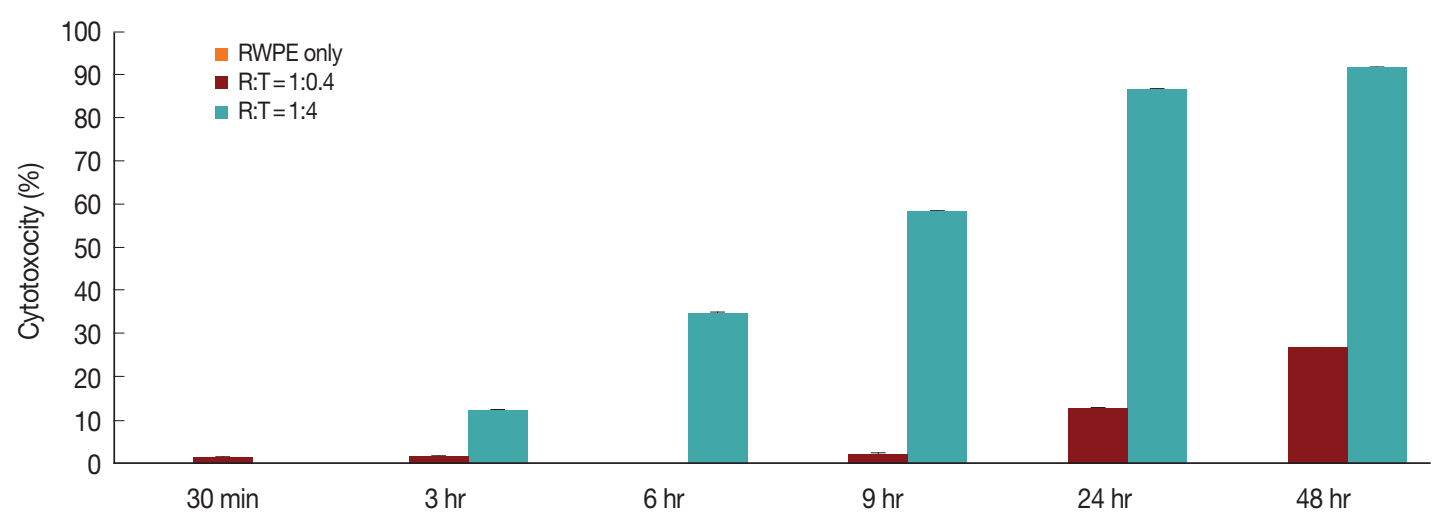

Fig. 1. Adherence of $T$. vaginalis to prostate epithelial cells (RWPE-1) and cytotoxicity of prostate epithelial cell. (A, B) T. vaginalis stained with CellTrackerOrange was added to a monolayer of prostate epithelial cells and was incubated for $48 \mathrm{hr}$. Orange colored T. vaginalis attached to prostate epithelial cells. Color intensity was measured by the ImageJ program. Bar $=100 \mu \mathrm{m}$. (C) Cytotoxicity of prostate epithelial cells infected with $T$. vaginalis. Prostate epithelial cells were incubated with $T$. vaginalis at a ratio of 1:0.4 and 1:4 for $48 \mathrm{hr}$. Cell cytotoxicity was measured by CCK-8 assay.

assumed to be an anaerobic condition. In addition, high concentration of zinc in the prostate may induce a critical cytotoxicity to T. vaginal [18]. Considering that prostate tissue is a harsh condition for T. vaginalis survival, only a few T. vaginalis organisms remained viable in the tissue. Thus, 1:0.4 was chosen to determine cytokine levels and EMT.

To investigate the production of inflammatory cytokines by infected prostate epithelial cells, RWPE-1 cells were incubated with T. vaginalis (1:0.4) for 6, 24, and $48 \mathrm{hr}$. The RWPE-1 cells released the cytokines IL-1 $\beta$, IL-6, CCL2, and CXCL8. Cytokine production was significantly greater in the infected group compared to the control group (Fig. 2). Production of IL-1 $\beta$ and CCL2 increased in a time-dependent manner (Fig. 2A, C), while the production of IL- 6 and CXCL8 increased for $24 \mathrm{hr}$ and sub- 
A

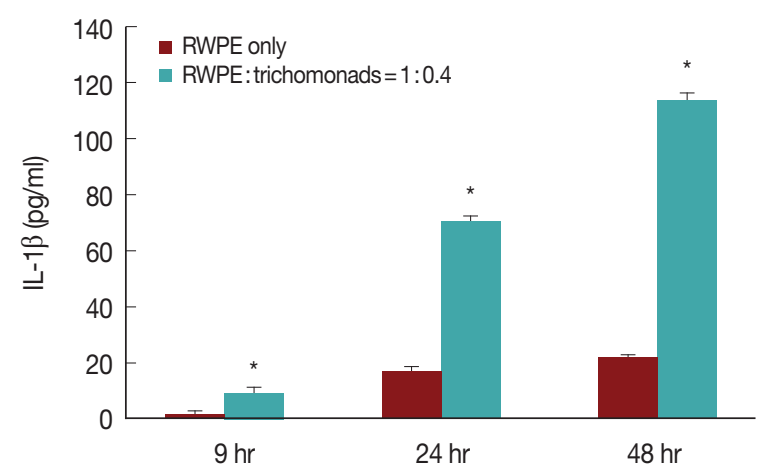

C

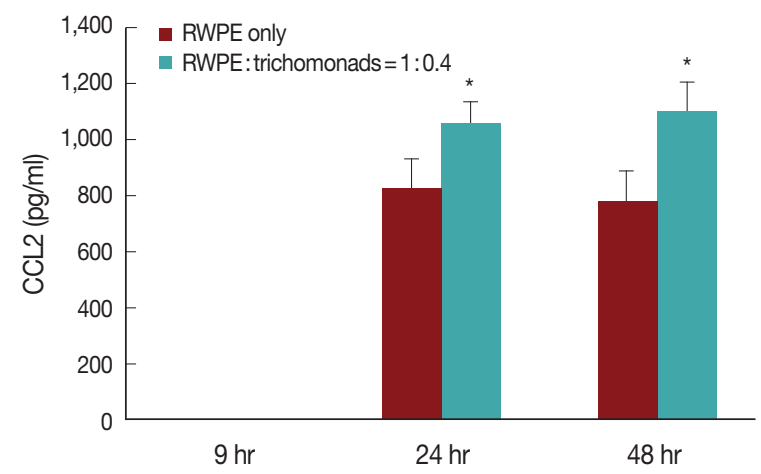

B

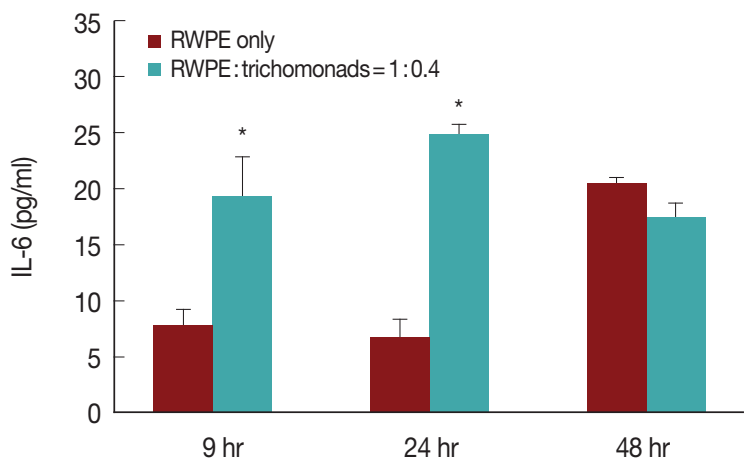

D

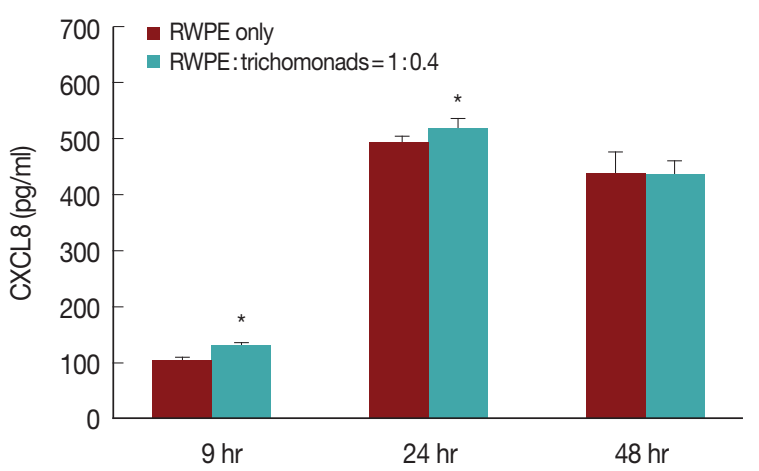

Fig. 2. Production of inflammatory cytokines by prostate epithelial cells stimulated with $T$. vaginalis (RWPE-1: T. vaginalis $=1: 0.4)$. When prostate epithelial cells were incubated with T. vaginalis for 9, 24, or $48 \mathrm{hr}$, prostate epithelial cells produced IL-1 13 (A), IL-6 (B), CCL2 (C), and CXCL8 (D). Each cytokine was measured by ELISA. IL-1 $\beta(A)$ and CCL2 (C) production increased in a time-dependent manner. ${ }^{*} P<0.05$ vs untreated RWPE-1. Statistical analyses were performed using SPSS statistical software, version 21 (IBM, Chicago, Illinois, USA). The Mann-Whitney $U$ test was used to compare the results, and $P$-values $<0.05$ were considered statistically significant. The data are expressed as the mean \pm SD of 3-4 independent experiments.

sequently decreased (Fig. 2B, D).

Several researchers have reported that the adhesion of T. vaginalis to vaginal epithelial cells plays an important role in the pathogenesis of trichomoniasis through production of CXCL8, CCL2, and IL-6 $[9,19,20]$. In previous studies, we reported that T. vaginalis-infected prostate epithelial cells produced pro-inflammatory cytokines such as IL-1 $\beta$, IL- 6 , CCL2, and CXCL8 [21,22], which is consistent with the present results (Fig. 2). Therefore, these pro-inflammatory cytokines may be produced as a result of adhesion of T. vaginalis to prostate epithelial cells, which could promote the pathogenesis of prostatic disease. However, further study is required to determine whether inhibition of adhesion with anti-adhesin antibody or chemicals affect cytotoxicity and cytokine production. Also, considering invasiveness of T. vaginalis, it is interesting to examine whether adhesion of trichomonads to prostate stromal cells might be related to stromal inflammation or proliferation.
Expression of EMT markers was measured by fluorescence microscopy and western blot. In this study, we confirmed EMT through decreased expression of E-cadherin (an epithelial cell marker) and increased expression of vimentin (a mesenchymal cell marker) (Fig. 3A, B). EMT is a biological process that allows a polarized epithelial cell to undergo multiple biochemical changes enabling it to assume a mesenchymal cell phenotype. Enhanced migratory capacity, invasiveness, elevated resistance to apoptosis, and greatly increased production of extracellular matrix components occur in EMT [23]. EMT may be classified into 3 subtypes. Type 1 EMT involves the transition of primordial epithelial cells into motile mesenchymal cells and is associated with the generation of diverse cell types during embryonic development and organogenesis. Type 3 EMT occurs in carcinoma cells. Type 2 EMT involves transition of secondary epithelial cells to resident tissue fibroblasts and is associated with wound healing, tissue regeneration, and organ 
A
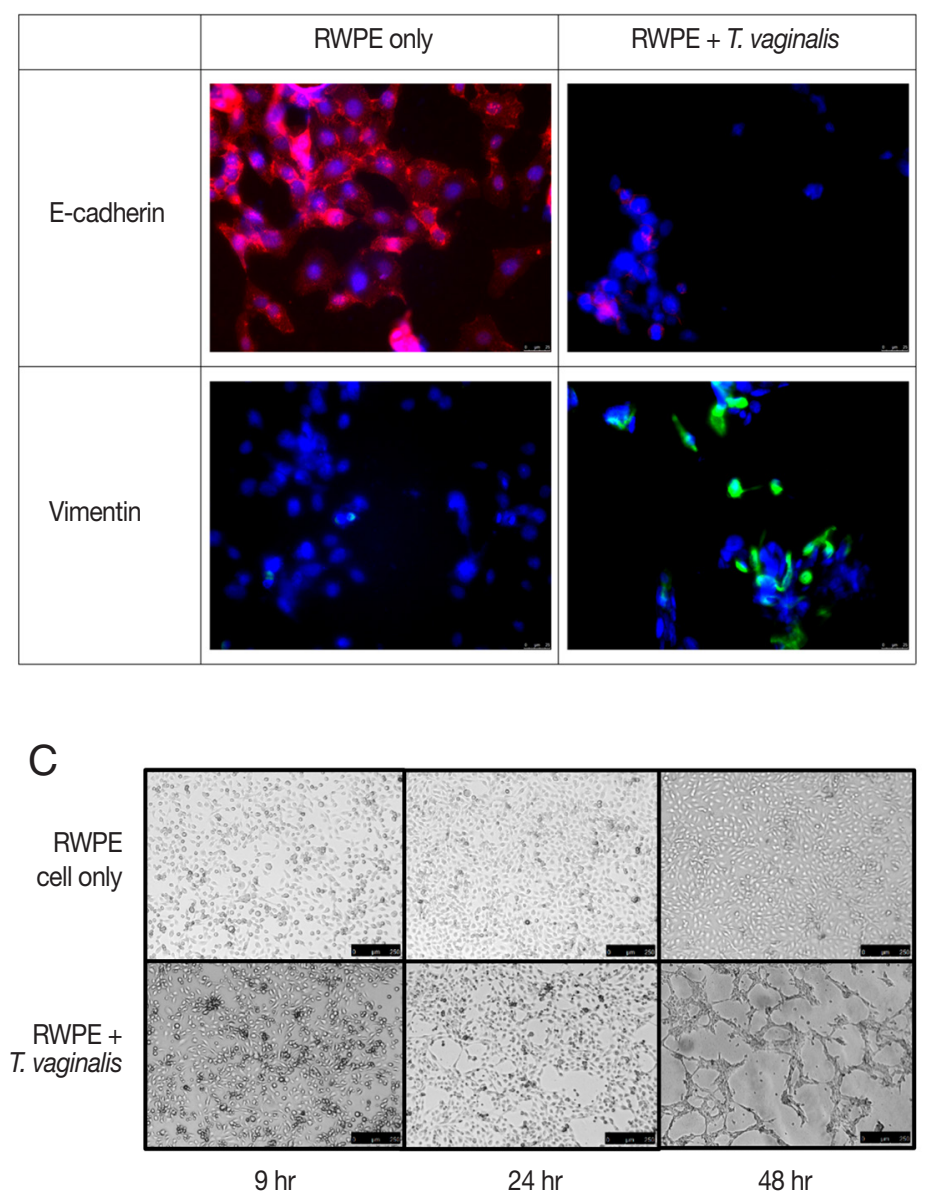

B

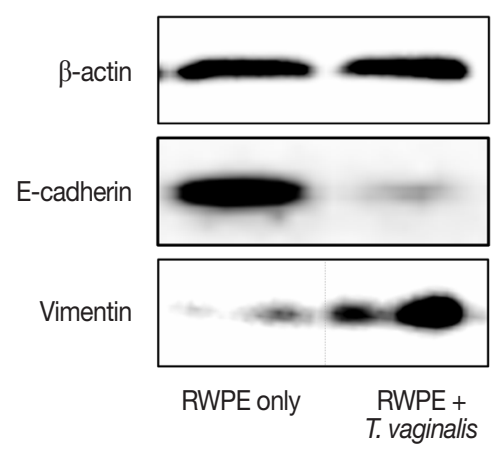

Fig. 3. Epithelial-mesenchymal transition (EMT) induced by prostate epithelial cells exposed to T. vaginalis (RWPE-1: T. vaginalis=1:0.4). (A, B) When prostate epithelial cells were infected with $T$. vaginalis for $48 \mathrm{hr}$, reduced E-cadherin (epithelial marker) expression and increased vimentin (mesenchymal marker) expression were observed by fluorescence microscopy after $24 \mathrm{hr}$ (A) and by western blot after $48 \mathrm{hr}$ (B). Bar $=25 \mu \mathrm{m}$. (C) The morphologic changes of prostate epithelial cells started at $24 \mathrm{hr}$ in response to $T$. vaginalis infection. Tube-like formation was observed at $48 \mathrm{hr}$. Bar $=250 \mu \mathrm{m}$. fibrosis [23-25]. Also, type 2 EMT is induced in response to inflammation, but stops once inflammation is attenuated, especially during wound healing and tissue regeneration [24]. In the present study, EMT of prostate epithelial cells was induced by T. vaginalis at 24 and $48 \mathrm{hr}$, along with increased cytotoxicity and cytokine production. Thus, our results indicate that EMT may be classified as type 2, which suggests a healing process in wounded prostate epithelial cells.

The ability of epithelial cells to change morphology to more closely resembled mesenchymal cells is a feature of EMT. Tube formation in vascular endothelial cells observed in cancer tissues is indicative of metastasis [26]. Maniotis et al. [27] showed that vascular mimicry patterns form in vitro in the absence of hemodynamic forces, suggesting that the formation of a patterned non-endothelial cell-lined microcirculation may be an attribute of the tumor cell. In this study, tube-like formation was observed after $48 \mathrm{hr}$ of incubation (Fig. 3C). Morphologic changes of prostate epithelial cells induced by EMT may lead to tube-like formation. We showed previously that T. vaginalis induced EMT in prostate epithelial cells [22]. In this study, we confirmed additional morphologic changes, as well as EMT.

In conclusion, adherence of T. vaginalis to prostate epithelial cells caused cytotoxicity, pro-inflammatory cytokine production, and EMT. Our findings suggested for the first time that $T$. vaginalis may induce inflammation via adhesion to normal prostate epithelial cells.

\section{ACKNOWLEDGMENT}

This research was supported by a National Research Foundation of Korea (NRF) grant funded by the Korean Government (MSIP) (no. NRF-2009-0074788).

\section{ETHICAL STANDARDS}

The experiments complied with the current laws of this country. 


\section{CONFLICT OF INTEREST}

The authors declare that they have no conflicts of interest.

\section{REFERENCES}

1. Abdolrasouli A, Amin A, Baharsefat M, Roushan A, Mofidi S. Persistent urethritis and prostatitis due to Trichomonas vaginalis: A case report. Can J Infect Dis Med Microbiol 2007; 18: 308-310.

2. World Health Organization. Global incidence and prevalence of selected curable sexually transmitted infections - 2008. Geneva, Switzerland. WHO. 2012, pp 1-20.

3. Seña AC, Miller WC, Hobbs MM, Schwebke JR, Leone PA, Swygard H, Atashili J, Cohen MS. Trichomonas vaginalis infection in male sexual partners: implications for diagnosis, treatment, and prevention. Clin Infect Dis 2007; 44: 13-22.

4. Sutcliffe S, Neace C, Magnuson NS, Reeves R, Alderete JF. Trichomonosis, a common curable STI, and prostate carcinogenesis-a proposed molecular mechanism. PLoS Pathog 2012; 8: e1002801.

5. Lee JJ, Moon HS, Lee TY, Hwang HS, Ahn MH, Ryu JS. PCR for diagnosis of male Trichomonas vaginalis infection with chronic prostatitis and urethritis. Korean J Parasitol 2012; 50: 157-159.

6. Mitteregger D, Aberle SW, Makristathis A, Walochnik J, Brozek W, Marberger M, Kramer G. High detection rate of Trichomonas vaginalis in benign hyperplastic prostatic tissue. Med Microbiol Immunol 2012; 201: 113-116.

7. Gardner WA, Jr., Culberson DE, Bennett BD. Trichomonas vaginalis in the prostate gland. Arch Pathol Lab Med 1986; 110: 430-432.

8. Alderete JF, Pearlman E. Pathogenic Trichomonas vaginalis cytotoxicity to cell culture monolayers. Br J Vener Dis 1984; 60: 99105.

9. Alderete JF, Garza GE. Specific nature of Trichomonas vaginalis parasitism of host cell surfaces. Infect Immun 1985; 50: 701-708.

10. Kim SR, Ryu JS. Scanning electron microscopic observation of Trichomonas vaginalis contacted with human vaginal epithelial cells. Korean J Electron Microscopy 2001; 31: 235-244.

11. Rendón-Maldonado JG, Espinosa-Cantellano M, González-Robles A, Martínez-Palomo A. Trichomonas vaginalis: in vitro phagocytosis of lactobacilli, vaginal epithelial cells, leukocytes, and erythrocytes. Exp Parasitol 1998; 89: 241-250.

12. Jesus JB, Vannier-Santos MA, Britto C, Godefroy P, Silva-Filho FC, Pinheiro AA, Rocha-Azevedo B, Lopes AH, Meyer-Fernandes JR. Trichomonas vaginalis virulence against epithelial cells and morphological variability: the comparison between a well-established strain and a fresh isolate. Parasitol Res 2004; 93: 369-377.
13. da Costa RF, de Souza W, Benchimol M, Alderete JF, MorgadoDiaz JA. Trichomonas vaginalis perturbs the junctional complex in epithelial cells. Cell Res 2005; 15: 704-716.

14. Benchimol M, de Andrade Rosa I, da Silva Fontes R, Burla Dias AJ. Trichomonas adhere and phagocytose sperm cells: adhesion seems to be a prominent stage during interaction. Parasitol Res 2008; 102: 597-604.

15. Vilela RC, Benchimol M. Trichomonas vaginalis and Tritrichomonas foetus: interaction with fibroblasts and muscle cells - new insights into parasite-mediated host cell cytotoxicity. Mem Inst Oswaldo Cruz 2012; 107: 720-727.

16. Lustig G, Ryan CM, Secor WE, Johnson PJ. Trichomonas vaginalis contact-dependent cytolysis of epithelial cells. Infect Immun 2013; 81: 1411-1419.

17. Leitsch D. Recent Advances in the Trichomonas vaginalis Field. F1000Res 2016; 5: 162.

18. Gimenes F, Souza RP, Bento JC, Teixeira JJ, Maria-Engler SS, Bonini MG, Consolaro ME. Male infertility: a public health issue caused by sexually transmitted pathogens. Nat Rev Urol 2014; 11: 672-687.

19. Kucknoor A, Mundodi V, Alderete JF. Trichomonas vaginalis adherence mediates differential gene expression in human vaginal epithelial cells. Cell Microbiol 2005; 7: 887-897.

20. Alderete JF, Lehker MW, Arroyo R. The Mechanisms and Molecules Involved in Cytoadherence and Pathogenesis of Trichomonas vaginalis. Parasitol Today 1995; 11: 70-74.

21. Seo MY, Im SJ, Gu NY, Kim JH, Chung YH, Ahn MH, Ryu JS. Inflammatory response of prostate epithelial cells to stimulation by Trichomonas vaginalis. Prostate 2014; 74: 441-449.

22. Han IH, Kim JH, Kim SS, Ahn MH, Ryu JS. Signalling pathways associated with IL-6 production and epithelial-mesenchymal transition induction in prostate epithelial cells stimulated with Trichomonas vaginalis. Parasite Immunol 2016; 38: 678-687.

23. Kalluri R, Weinberg RA. The basics of epithelial-mesenchymal transition. J Clin Invest 2009; 119: 1420-1428.

24. Lee K, Nelson CM. New insights into the regulation of epithelial-mesenchymal transition and tissue fibrosis. Int Rev Cell Mol Biol 2012; 294: 171-221.

25. Zeisberg M, Neilson EG. Biomarkers for epithelial-mesenchymal transitions. J Clin Invest 2009; 119: 1429-1437.

26. Folberg R, Hendrix MJ, Maniotis AJ. Vasculogenic mimicry and tumor angiogenesis. Am J Pathol 2000; 156: 361-381.

27. Maniotis AJ, Folberg R, Hess A, Seftor EA, Gardner LM, Pe'er J, Trent JM, Meltzer PS, Hendrix MJ. Vascular channel formation by human melanoma cells in vivo and in vitro: vasculogenic mimicry. Am J Pathol 1999; 155: 739-752. 